Brazilian Journal

of Chemical

Engineering

\title{
MEASUREMENTS AND THERMODYNAMIC MODELING OF VAPOR-LIQUID EQUILIBRIA FOR BINARY SYSTEMS OF ISOPROPYL CHLOROACETATE WITH CYCLOHEXANE, ISOPROPANOL AND BENZENE AT $101.3 \mathrm{kPa}$
}

\author{
Dongmei $\mathrm{Xu}^{1}$, Rui $\mathrm{Li}^{1}$, Lianzheng Zhang ${ }^{1}$, Yixin $\mathrm{Ma}^{1}$, \\ Jun $\mathrm{Gao}^{1 *}$ and Yinglong Wang ${ }^{2}$ \\ 'Shandong University of Science and Technology, College of Chemical and Environmental Engineering, Qingdao, China.
ORCID: 0000-0002-5770-0513; ORCID: 0000-0003-4827-7941; ORCID: 0000-0003-0894-5909; E-mail: gao@sdust.edu.cn -
ORCID: 0000-0003-1145-9565
Qingdao University of Science and Technology, College of Chemical Engineering, Qingdao, China. ORCID: 0000-0002-3043-0891
}

(Submitted: March 1, 2019 ; Revised: April 24, 2019 ; Accepted: June 3, 2019)

\begin{abstract}
In this work, the vapor-liquid equilibrium experimental data for the systems of isopropyl chloroacetate + isopropanol, isopropyl chloroacetate + cyclohexane and isopropyl chloroacetate + benzene were measured by a modified Rose-type recirculating still under the pressure of $101.3 \mathrm{kPa}$. The thermodynamic consistency of the measured data was verified by the Herington and van Ness methods, respectively. The experimental data were correlated by the NRTL, Wilson, and UNIQUAC activity coefficient models, and the corresponding interaction parameters of the three models were obtained. The root-mean-square deviations between the experimental data and calculated results for the temperature and the mole fraction of the vapor phase were less than $0.58 \mathrm{~K}$ and 0.0066 , respectively. In addition, the excess Gibbs energy was calculated for the three systems.

Keywords: Vapor-liquid equilibrium; Isopropyl chloroacetate; Correlation; Thermodynamic model.
\end{abstract}

\section{INTRODUCTION}

Isopropyl chloroacetate is a raw material and intermediate, which is widely used in the synthesis of nonsteroidal anti-inflammatory drugs, such as naproxen, ketoprofen and ibupofen. Generally, isopropyl chloroacetate can be synthesized by esterification of chloroacetic acid and isopropanol with a catalyst, such as cation exchange resin (Patwardhan and Sharma, 1990), inorganic salts (Liu and You, 2013), and ionic liquids (Liu et al., 2007). During the esterification process, the water-carrying agent is required to remove water continuously to increase the esterification yield. Ma et al. (2006) reported the synthesis of isopropyl chloroacetate using cyclohexane as a water-carrying agent in their work. Wang et al. (2003) used benzene as a water-carrying agent to separate water from the esterification process. After the reaction, a mixture of isopropyl chloroacetate, unreacted isopropanol and water-carrying agent is obtained. To separate isopropyl chloroacetate from the mixture by distillation, vaporliquid equilibrium (VLE) data are required.

Until now, some works have reported the preparation of isopropyl chloroacetate (Xu et al., 2011; Liu and You, 2012). However, for separation of isopropyl chloroacetate from the reacted solution, the VLE data for the systems of isopropyl chloroacetate + isopropanol, isopropyl chloroacetate + cyclohexane and isopropyl chloroacetate + benzene have not been reported in the NIST database. Therefore, it is necessary to generate the VLE data for these systems, which can be useful for the separation and purification

\footnotetext{
* Corresponding author: Jun Gao - E-mail: gao@sdust.edu.cn
} 
of isopropyl chloroacetate from the mixture by distillation.

In this work, the VLE data for the systems isopropyl chloroacetate + isopropanol, isopropyl chloroacetate + cyclohexane and isopropyl chloroacetate + benzene were measured under the pressure of $101.3 \mathrm{kPa}$. To ensure the reliability of the measured VLE data, the thermodynamic consistency test was performed by the Herington and van Ness method. The non-random two-liquid (NRTL) (Renon and Prausnitz, 1968; Liu et al., 2019), Wilson (Wilson, 1964; Li, 2014), and the universal quasi-chemical (UNIQUAC) (Abrams and Prausnitz, 1975) activity coefficient models were used to correlate the experimental VLE data and the binary interaction parameters for the three models were regressed. In addition, the calculation of the excess Gibbs energy for the three systems from the VLE data was listed.

\section{EXPERIMENTAL}

\section{Chemicals}

Isopropyl chloroacetate, cyclohexane, isopropanol and benzene were commercial grade chemicals in this work. The mass purities of isopropyl chloroacetate, cyclohexane, isopropanol and benzene were 0.980, 0.995, 0.997 and 0.995, respectively, which were confirmed by gas chromatography (GC) and all the reagents were used directly. The boiling point temperatures for the chemicals were determined by a modified Rose-type recirculating still. The relevant information of the chemicals, such as CAS number, supplier, boiling temperature and so on, is given in Table 1.

\section{Apparatus and procedure}

The apparatus used in this work was a modified Rose-type recirculating still which is presented in detail in Figure 1. The equilibrium temperature was determined by a mercury thermometer with the accuracy of $\pm 0.1 \mathrm{~K}$. The pressure was measured by a mercury U-shaped manometer and the accuracy of the manometer was $\pm 0.1333 \mathrm{kPa}$. In each experiment, a liquid mixture of $50 \mathrm{ml}$ was charged into the equilibrium still and heated. The vapor condensate was recirculated and mixed with the liquid in the still, which could make enough contact for the two phases.

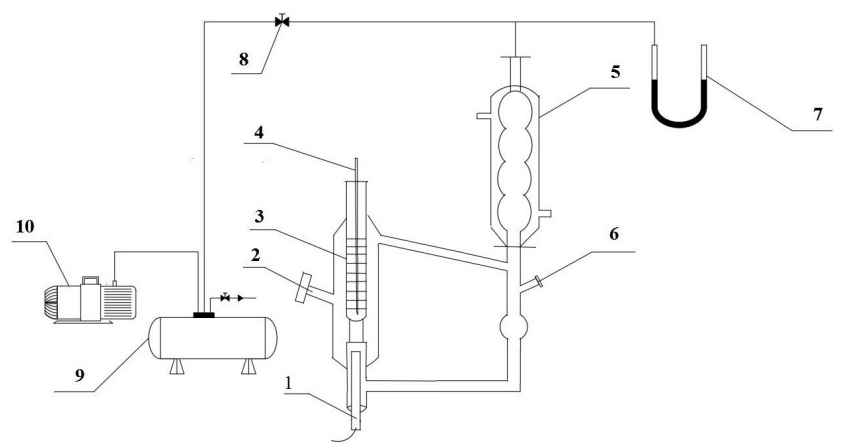

Figure 1. The vapor-liquid equilibrium apparatus: 1, heating rod; 2, liquid phase sample port; 3, thermometer sleeve tube; 4, mercury thermometer; 5 , condenser; 6 , vapor phase sample port, 7 , mercury U-shaped manometer, 8, needle valve, 9, buffer tank, 10, vacuum pump.

To reach the equilibrium state, the recirculation time for the two phases was maintained for at least 50 min at a constant temperature, then the equilibrium temperature was recorded. At the same time, $0.3 \mathrm{ml}$ of the vapor and the liquid phases were withdrawn by syringe for analysis, respectively. All the samples were analyzed by GC.

Gas chromatography (GC7900, Shanghai Tianmei Scientific Instrument Co., Ltd.) was used to analyze the samples, which was equipped with a flame ionization detector (FID) and a capillary column. The carrier gas was high-purity nitrogen with the purity of 99.999 $\mathrm{wt} \%$. The compositions of all samples were obtained by a T2000P GC workstation. The detailed operating conditions are shown in Table 2.

Table 2. Operating conditions for the gas chromatograph.

\begin{tabular}{lll}
\hline \multicolumn{1}{c}{ Name } & Characteristic & \multicolumn{1}{c}{ Description } \\
\hline \multirow{3}{*}{ Column } & Type & DB-WAX, 30 $\mathrm{m} \times 0.53 \mathrm{~m} \times$ \\
& Temperature & $0.5 \mu \mathrm{m}$ \\
Carrier & Type & Nitrogen \\
gas & Flow rate & $10 \mathrm{~mL} / \mathrm{min}$ \\
& Pressure & $0.3 \mathrm{MPa}$ \\
\multirow{2}{*}{ Injector } & Injection & $0.2 \mu \mathrm{L}$ \\
& volume & $443.15 \mathrm{~K}$ \\
& Temperature & Flame ionization detector \\
Detector & Type & (FID) \\
& Temperature & $433.15 \mathrm{~K}$ \\
\hline
\end{tabular}

Table 1. Information of the chemicals.

\begin{tabular}{|c|c|c|c|c|c|c|}
\hline \multirow{2}{*}{ Name } & \multirow{2}{*}{ CAS } & \multirow{2}{*}{ Supplier $^{c}$} & \multirow{2}{*}{$\begin{array}{c}\text { Mass } \\
\text { fraction }\end{array}$} & \multicolumn{2}{|r|}{$\mathbf{T}_{\mathbf{b}} / \mathbf{K}^{\mathbf{b}}$} & \multirow{2}{*}{$\begin{array}{l}\text { Analysis } \\
\text { method }\end{array}$} \\
\hline & & & & This work & Literature & \\
\hline Isopropyl chloroacetate & $105-48-6$ & (1) & $\geq 0.980$ & 422.85 & 422.63 (Dorris et al., 1934) & $\mathrm{GC}^{\mathrm{a}}$ \\
\hline Isopropanol & $67-63-0$ & (2) & $\geq 0.997$ & 355.11 & 355.45 (Chen et al., 2011) & $\mathrm{GC}^{\mathrm{a}}$ \\
\hline Cyclohexane & $110-82-7$ & (2) & $\geq 0.995$ & 353.83 & 353.65 (Gupta and Lee, 2012) & $\mathrm{GC}^{\mathrm{a}}$ \\
\hline Benzene & $71-43-2$ & (3) & $\geq 0.995$ & 353.23 & 353.25 (Li et al., 2017) & $\mathrm{GC}^{\mathrm{a}}$ \\
\hline
\end{tabular}

${ }^{\mathrm{a}}$ Gas chromatography. ${ }^{\mathrm{b}}$ The boiling temperature was measured at $101.3 \mathrm{kPa}$. The standard uncertainties $u$ of $P$ and $T$ are $u(P)=0.35 \mathrm{kPa}, u(T)=0.35 \mathrm{~K} .{ }^{\mathrm{c}}$ Suppliers: $(1) \mathrm{TCI}($ Shanghai) Development Co., Ltd.; (2) Tianjin Kemio Chemical Co., Ltd., (3) Tianjin Fuyu Chemical Co., Ltd. 


\section{Analysis}

Before analyzing the compositions of the samples, the area correction normalization method (Dai et al., 2014; Wu et al., 2018) was applied to calibrate the GC in this work. First, five different standard samples were prepared gravimetrically with an AR1140 electronic balance (Ohaus Corporation) with an accuracy of \pm $0.0001 \mathrm{~g}$. The five different standard samples with known compositions were analyzed by GC and the peak area of GC was calibrated. The samples of the vapor and liquid phases were analyzed at least three times, and the average values were recorded.

\section{RESULTS AND DISCUSSIONS}

\section{Experimental VLE results}

The experimental VLE data of isopropyl chloroacetate + isopropanol, isopropyl chloroacetate + cyclohexane and isopropyl chloroacetate +benzene were measured at the pressure of $101.3 \mathrm{kPa}$ and are listed in Table 3. The T-x-y profiles for the three systems are plotted in Figures 2-4.

The equilibrium relationship of the system is represented by the following equation (Smith et al., 2001):

$\hat{\phi}_{i} y_{i} p=x_{i} \gamma_{i} \phi_{i}^{s} p_{i}^{s} \exp \left[\frac{V_{i}^{L}\left(p-p_{i}^{s}\right)}{R T}\right]$

Generally, the exponential term $\exp \left[\mathrm{V}_{\mathrm{i}}^{\mathrm{L}}\left(\left(\mathrm{p}-\mathrm{p}_{\mathrm{i}}^{\mathrm{s}}\right)^{\mathrm{s}}\right) /\right.$ $\mathrm{RT})$ ] is approximately equal to 1 under atmospheric pressure. In addition, the vapor phase could be regarded as an ideal gas, thus $\phi_{\mathrm{i}}$ and $\phi_{\mathrm{i}}^{\mathrm{s}}$ are equal to 1 . Thus, Eq. 1 can be simplified as follows:

$\mathrm{y}_{\mathrm{i}} \mathrm{p}=\mathrm{x}_{\mathrm{i}} \gamma_{\mathrm{i}} \mathrm{p}_{\mathrm{i}}^{\mathrm{s}}$

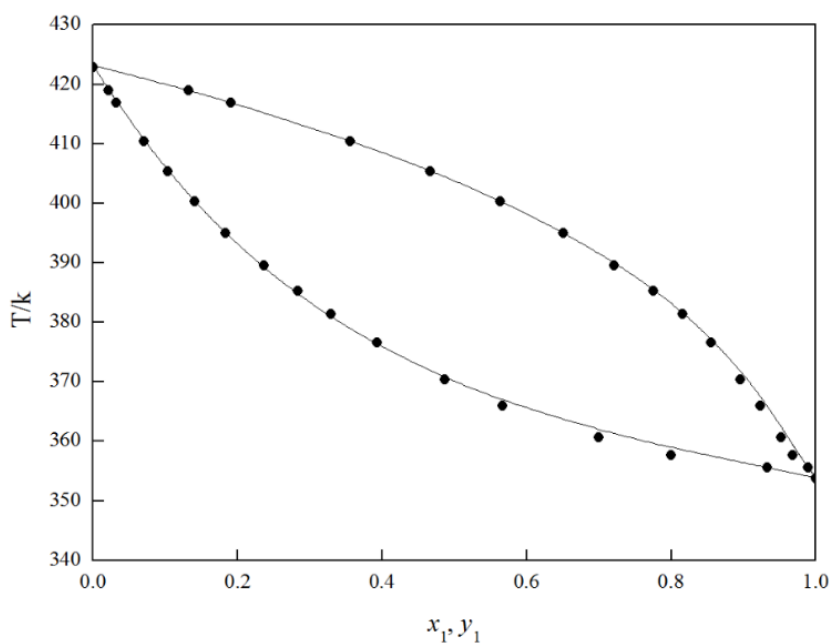

Figure 2. $T-x-y$ phase equilibrium for the system cyclohexane (1) + isopropyl chloroacetate (2) at 101.3 $\mathrm{kPa}: \bullet$, experimental data; - , calculated by the NRTL model.
Table 3. Experimental VLE data for temperature $T$, liquid phase mole fraction $x$, vapor phase mole fraction $y_{i}$, activity coefficient $\gamma$, excess Gibbs energy $G^{E}$, the results for cyclohexane (1) + isopropyl chloroacetate (2), isopropanol (1) + isopropyl chloroacetate (2) and benzene (1) + isopropyl chloroacetate (2) at 101.3kPa. ${ }^{\mathrm{a}}$

\begin{tabular}{|c|c|c|c|c|c|}
\hline $\begin{array}{c}T \\
(\mathbf{K})\end{array}$ & $x_{1}$ & $y_{1}$ & $\gamma_{1}$ & $\gamma_{2}$ & $\begin{array}{c}G^{E} \\
\left(\mathbf{J} \cdot \mathbf{m o l}^{-1}\right)\end{array}$ \\
\hline \multicolumn{6}{|c|}{ Cyclohexane (1) + Isopropyl chloroacetate (2) } \\
\hline 353.83 & 1.0000 & 1.0000 & - & - & 0.00 \\
\hline 355.65 & 0.9333 & 0.9894 & 1.0046 & 1.6575 & 112.32 \\
\hline 357.64 & 0.8000 & 0.9685 & 1.0818 & 1.5090 & 431.71 \\
\hline 360.60 & 0.7001 & 0.9519 & 1.1149 & 1.3574 & 503.03 \\
\hline 366.02 & 0.5667 & 0.9239 & 1.1470 & 1.1921 & 468.21 \\
\hline 370.33 & 0.4870 & 0.8961 & 1.1503 & 1.1599 & 444.25 \\
\hline 376.60 & 0.3932 & 0.8549 & 1.1510 & 1.0789 & 317.42 \\
\hline 381.35 & 0.3297 & 0.8162 & 1.1603 & 1.0393 & 237.34 \\
\hline 385.20 & 0.2835 & 0.7755 & 1.1645 & 1.0352 & 217.65 \\
\hline 389.60 & 0.2366 & 0.7215 & 1.1662 & 1.0344 & 201.46 \\
\hline 394.96 & 0.1837 & 0.6508 & 1.1932 & 1.0125 & 139.85 \\
\hline 400.25 & 0.1403 & 0.5634 & 1.1976 & 1.0116 & 117.18 \\
\hline 405.30 & 0.1035 & 0.4668 & 1.2017 & 1.0100 & 94.14 \\
\hline 410.45 & 0.0700 & 0.3560 & 1.2117 & 1.0043 & 59.49 \\
\hline 416.85 & 0.0323 & 0.1903 & 1.2270 & 1.0041 & 36.62 \\
\hline 418.96 & 0.0215 & 0.1325 & 1.2288 & 1.0011 & 19.18 \\
\hline 422.85 & 0.0000 & 0.0000 & - & - & 0.00 \\
\hline \multicolumn{6}{|c|}{ Isopropanol (1) + Isopropyl chloroacetate (2) } \\
\hline 355.11 & 1.0000 & 1.0000 & - & - & 0.00 \\
\hline 356.22 & 0.9393 & 0.9921 & 1.0204 & 1.3246 & 106.71 \\
\hline 357.35 & 0.8894 & 0.9858 & 1.0240 & 1.2454 & 134.78 \\
\hline 359.79 & 0.7955 & 0.9716 & 1.0260 & 1.2157 & 180.56 \\
\hline 362.53 & 0.7006 & 0.9545 & 1.0305 & 1.1879 & 218.83 \\
\hline 368.66 & 0.5283 & 0.9102 & 1.0383 & 1.1638 & 280.17 \\
\hline 371.49 & 0.4636 & 0.8865 & 1.0411 & 1.1587 & 301.70 \\
\hline 375.45 & 0.3785 & 0.8511 & 1.0657 & 1.1285 & 309.71 \\
\hline 380.45 & 0.2962 & 0.8063 & 1.0888 & 1.0777 & 246.29 \\
\hline 385.90 & 0.2273 & 0.7512 & 1.1060 & 1.0379 & 165.69 \\
\hline 390.95 & 0.1734 & 0.6897 & 1.1351 & 1.0164 & 115.13 \\
\hline 399.05 & 0.1055 & 0.5654 & 1.1980 & 1.0059 & 80.69 \\
\hline 405.45 & 0.0662 & 0.4446 & 1.2493 & 1.0053 & 66.31 \\
\hline 409.75 & 0.0457 & 0.3548 & 1.2820 & 1.0016 & 43.87 \\
\hline 415.00 & 0.0235 & 0.2283 & 1.3933 & 1.0011 & 30.60 \\
\hline 422.85 & 0.0000 & 0.0000 & - & - & 0.00 \\
\hline \multicolumn{6}{|c|}{ Benzene (1) + Isopropyl chloroacetate (2) } \\
\hline 353.23 & 1.0000 & 1.0000 & - & - & 0.00 \\
\hline 356.77 & 0.8825 & 0.9868 & 1.0039 & 1.1169 & 48.72 \\
\hline 359.88 & 0.7916 & 0.9734 & 1.0063 & 1.1131 & 81.69 \\
\hline 361.80 & 0.7342 & 0.9633 & 1.0150 & 1.1121 & 117.83 \\
\hline 368.34 & 0.5828 & 0.9251 & 1.0192 & 1.1114 & 168.89 \\
\hline 373.95 & 0.4761 & 0.8834 & 1.0214 & 1.1093 & 200.30 \\
\hline 378.05 & 0.4102 & 0.8490 & 1.0217 & 1.0944 & 194.90 \\
\hline 385.05 & 0.3141 & 0.7789 & 1.0223 & 1.0706 & 171.97 \\
\hline 389.55 & 0.2590 & 0.7234 & 1.0297 & 1.0602 & 164.84 \\
\hline 396.65 & 0.1875 & 0.6209 & 1.0294 & 1.0445 & 134.57 \\
\hline 401.45 & 0.1414 & 0.5418 & 1.0655 & 1.0230 & 95.11 \\
\hline 407.85 & 0.0892 & 0.4121 & 1.1125 & 1.0132 & 72.75 \\
\hline 413.65 & 0.0456 & 0.2718 & 1.2652 & 1.0057 & 55.55 \\
\hline 415.90 & 0.0262 & 0.2089 & 1.6134 & 1.0023 & 51.07 \\
\hline 418.85 & 0.0135 & 0.1272 & 1.7921 & 1.0022 & 34.98 \\
\hline 422.85 & 0.0000 & 0.0000 & - & - & 0.00 \\
\hline
\end{tabular}
$u(y)=0.0122$ 


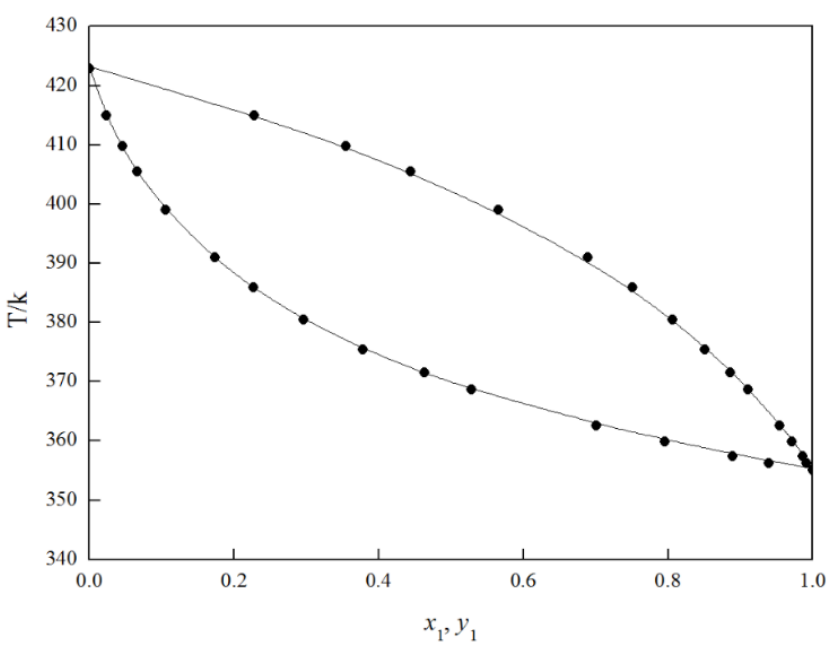

Figure 3. T-x-y phase equilibrium for the system isopropanol (1) + isopropyl chloroacetate (2) at 101.3 $\mathrm{kPa}: \bullet$, experimental data; _ _, calculated by the NRTL model.

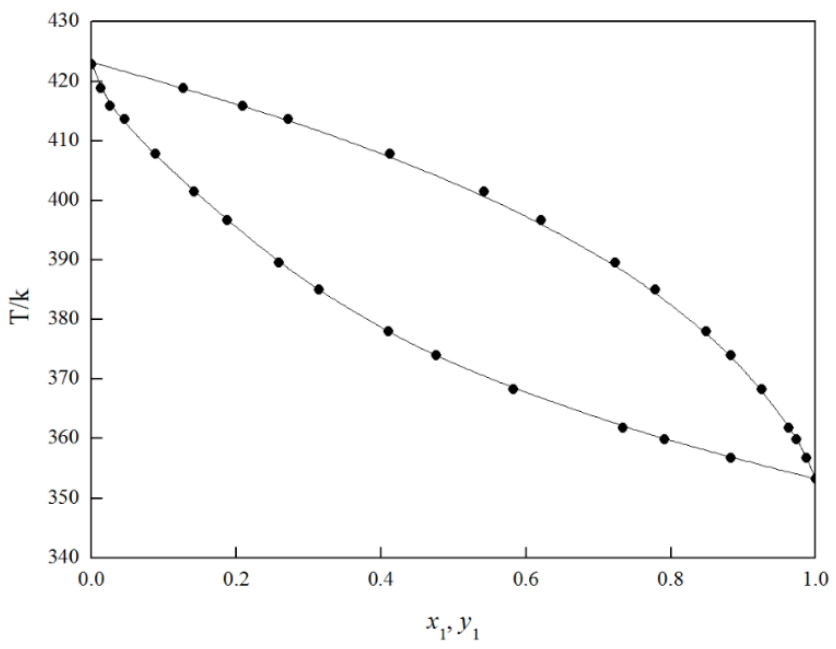

Figure 4. $T-x-y$ phase equilibrium for the system benzene (1) + isopropyl chloroacetate (2) at 101.3 $\mathrm{kPa}: \bullet$, experimental data; _ - calculated by the NRTL model.

The $\mathrm{p}_{\mathrm{i}}^{\mathrm{s}}$ can be calculated by the Wagner 25 equation (Forero and Velásquez, 2011; Gao et al., 2016b):

$\ln \left(\mathrm{p}_{\mathrm{i}}^{\mathrm{s}}\right)=\ln \left(\mathrm{p}_{\mathrm{ci}}\right)+\frac{\mathrm{C}_{1 \mathrm{i}}\left(1-\mathrm{T}_{\mathrm{ri}}\right)+\mathrm{C}_{2 \mathrm{i}}\left(1-\mathrm{T}_{\mathrm{ri}}\right)^{1.5}+\mathrm{C}_{3 \mathrm{i}}\left(1-\mathrm{T}_{\mathrm{ri}}\right)^{2.5}+\mathrm{C}_{4 \mathrm{i}}\left(1-\mathrm{T}_{\mathrm{ri}}\right)^{5}}{\mathrm{~T}_{\mathrm{ri}}}$

and
$\mathrm{T}_{\mathrm{ri}}=\frac{\mathrm{T}}{\mathrm{T}_{\mathrm{ci}}}$

The Wagner 25 parameters $C_{1 i}$ to $C_{4 i}$, as well as the $T_{r i}$ and $T_{c i}$ for each pure component $i$, were taken from the Aspen Plus physical properties databank and listed in Table 4. In the meantime, the activity coefficient was calculated by Eq. 2, and the results are listed in Table 3.

To evaluate the non-ideality of the three binary systems, the excess Gibbs energy $G^{E}$ (Acevedo et al., 1988; Shi et al., 2017) was calculated as follows:

$\mathrm{G}^{\mathrm{E}}=\mathrm{RT}\left(\mathrm{x}_{1} \ln \gamma_{1}+\mathrm{x}_{2} \ln \gamma_{2}\right)$

The calculated results of $G^{E}$ are presented in Table 3 and Figure 5. As shown in Figure 5, the three binary systems exhibit positive deviations from Raoult's law, which indicates the non-ideality of the solutions for three binary systems. Furthermore, the values of the excess Gibbs free energy for three binary systems follow the order of isopropyl chloroacetate + cyclohexane $>$ isopropyl chloroacetate + isopropanol $>$ isopropyl chloroacetate + benzene.

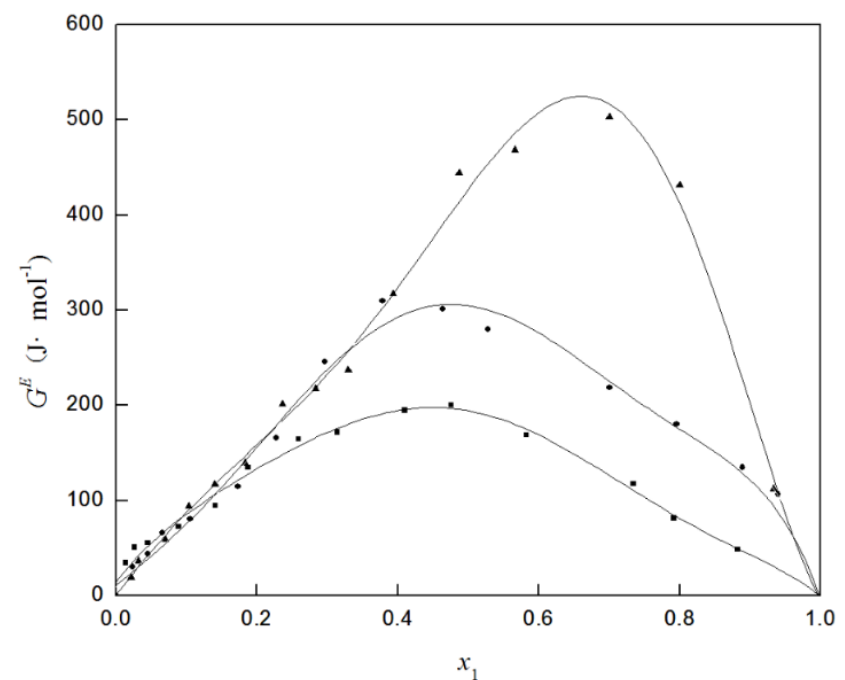

Figure 5. Excess Gibbs energy for the three systems at $101.3 \mathrm{kPa}: \boldsymbol{\Delta}$, cyclohexane (1) + isopropyl chloroacetate (2); •, isopropanol (1) + isopropyl chloroacetate (2); $\mathbf{a}$, benzene (1) + isopropyl chloroacetate (2),--, calculated by the NRTL model.

Table 4. Parameters of the Wagner 25 equation. ${ }^{\mathrm{a}}$

\begin{tabular}{lcccccccc}
\hline \multicolumn{1}{c}{ Component } & $\boldsymbol{C}_{\boldsymbol{1 i}}$ & $\boldsymbol{C}_{\boldsymbol{2 i}}$ & $\boldsymbol{C}_{\boldsymbol{3 i}}$ & $\boldsymbol{C}_{\boldsymbol{4 i}}$ & $\boldsymbol{p}_{\boldsymbol{c}} / \mathbf{k} \mathbf{\mathbf { P a }}$ & $\boldsymbol{T}_{\boldsymbol{c}} / \mathbf{K}$ & $\boldsymbol{T}_{\text {lower }} / \mathbf{K}$ & $\boldsymbol{T}_{\text {upper }} / \mathbf{K}$ \\
\hline Isopropyl chloroacetate & -8.3736 & 2.2903 & -3.9060 & -3.7705 & 3420.33 & 614.00 & 190.00 & 614.00 \\
Cyclohexane & -7.0580 & 1.7024 & -2.1203 & -3.1898 & 4070.44 & 553.40 & 279.82 & 553.40 \\
Isopropanol & -8.5396 & 1.5379 & -7.6671 & 2.3246 & 4751.67 & 508.27 & 185.24 & 508.27 \\
Benzene & -7.1463 & 1.9153 & -2.2948 & -3.2081 & 4894.12 & 562.02 & 278.47 & 562.02 \\
\hline
\end{tabular}

a Taken from the Aspen Plus Physical Properties Databank. 


\section{Thermodynamic consistency tests}

For the binary mixtures, the Herington and van Ness method were used to check the consistency of the experimental data.

The Herington method (Herington and Inst, 1951; Alinejhad et al., 2018) based on the Gibbs-Duhem theory was adopted which can be described as follows:

$\mathrm{D}=100 \times\left|\frac{\mathrm{S}_{+}-\mathrm{S}_{-}}{\mathrm{S}_{+}+\mathrm{S}_{-}}\right|=100 \times \frac{\left|\int_{0}^{1} \ln \left(\gamma_{1} / \gamma_{2}\right) \mathrm{d} \mathrm{x}_{1}\right|}{\int_{0}^{1} \ln \left(\gamma_{1} / \gamma_{2}\right) \mid \mathrm{d} \mathrm{x}_{1}}$

$\mathrm{J}=150 \times\left|\frac{\mathrm{T}_{\max }-\mathrm{T}_{\min }}{\mathrm{T}_{\min }}\right|$

The $\ln \left(\gamma_{1} / \gamma_{2}\right)$ vs $x$ diagram is shown in Figure 6 and $T_{\max }$ and $T_{\min }$ are the maximum and minimum boiling points, respectively. The criterion of the Herington test is that the absolute value of $|D-J|$ should be less than 10. As shown in Table 5, the results of thermodynamic consistency for all three systems are all less than 10 , which indicates that the experimental data of the three systems passed the thermodynamic consistency test.

The van Ness test method (Van Ness et al., 1973; Gao et al., 2016a) is expressed by the following equations:

$$
\begin{aligned}
& \Delta y=\frac{1}{N} \sum_{i=1}^{N} \Delta y_{i}=\frac{1}{N} \sum_{i=1}^{N} 100\left|y_{i}^{\text {cal }}-y_{i}^{\text {exp }}\right| \\
& \Delta P=\frac{1}{N} \sum_{i=1}^{N} \Delta p_{i}=\frac{1}{N} \sum_{i=1}^{N} 100\left|\frac{P_{i}^{\text {exp }}-P_{i}^{\text {cal }}}{P_{i}^{\text {exp }}}\right|
\end{aligned}
$$

The obtained VLE data can pass the thermodynamic consistency test if the values of $\Delta y$ and $\Delta P$ are both less than 1 . The test results are presented in Table 6. As seen from Table 6 , the results of $\Delta y$ and $\Delta P$ are all less than unity, which indicates that the measured VLE data are thermodynamically consistent.

\section{VLE data correlation}

The measured experimental VLE data were correlated by the NRTL, Wilson and UNIQUAC activity coefficient models. For the UNIQUAC model, the structural parameters $r$ and $q$ are presented in Table 7. The expressions of the activity coefficient models are as follows:

$$
\text { NRTL: }
$$

Table 6. van Ness test for thermodynamic consistency check.

\begin{tabular}{clcc}
\hline System & & $\mathbf{\Delta P}<\mathbf{1}$ & $\boldsymbol{\Delta y}<\mathbf{1}$ \\
\hline Cyclohexane (1) & NRTL & 0.16 & $\mathbf{0 . 5 0 8 2}$ \\
+ & Wilson & 0.15 & 0.4951 \\
Isopropyl chloroacetate (2) & UNIQUAC & 0.15 & 0.4901 \\
Isopropanol (1) & NRTL & 0.06 & 0.2745 \\
+ & Wilson & 0.06 & 0.2495 \\
Isopropyl chloroacetate (2) & UNIQUAC & 0.08 & 0.2745 \\
Benzene (1) & NRTL & 0.09 & 0.4439 \\
+ & Wilson & 0.06 & 0.2604 \\
Isopropyl chloroacetate (2) & UNIQUAC & 0.08 & 0.4974 \\
\hline
\end{tabular}

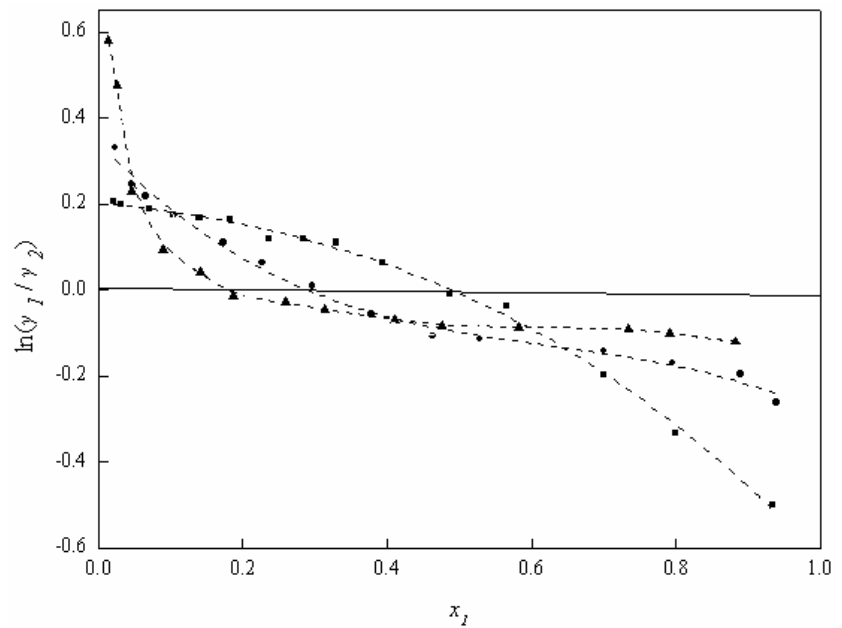

Figure 6. $\ln \left(\gamma_{1} / \gamma_{2}\right)$ vs. $x_{1}$ plot for the three systems: a, cyclohexane (1) + isopropyl chloroacetate (2); •, isopropanol (1) + isopropyl chloroacetate (2); $\boldsymbol{\Delta}$, benzene (1) + isopropyl chloroacetate (2), --, calculated by the NRTL model.

$$
\begin{aligned}
& \ln \gamma_{\mathrm{i}}=\frac{\sum_{\mathrm{j}} \mathrm{x}_{\mathrm{j}} \tau_{\mathrm{ji}} \mathrm{G}_{\mathrm{ji}}}{\sum_{\mathrm{k}} \mathrm{x}_{\mathrm{k}} \mathrm{G}_{\mathrm{ki}}}+\sum_{\mathrm{j}} \frac{\mathrm{x}_{\mathrm{j}} \mathrm{G}_{\mathrm{ij}}}{\sum_{\mathrm{k}} \mathrm{x}_{\mathrm{k}} \mathrm{G}_{\mathrm{kj}}}\left(\tau_{\mathrm{ij}}-\frac{\sum_{\mathrm{m}} \mathrm{x}_{\mathrm{m}} \tau_{\mathrm{mj}} \mathrm{G}_{\mathrm{mj}}}{\sum_{\mathrm{k}} \mathrm{x}_{\mathrm{k}} \mathrm{G}_{\mathrm{kj}}}\right) \\
& \tau_{\mathrm{ij}}=\mathrm{a}_{\mathrm{ij}}+\frac{\mathrm{b}_{\mathrm{ij}}}{\mathrm{T}}, \mathrm{G}_{\mathrm{ij}}=\exp \left(-\alpha_{\mathrm{ij}} \tau_{\mathrm{ij}}\right) \\
& \quad \alpha_{\mathrm{ij}}=0.3 \\
& \text { Wilson: }
\end{aligned}
$$

$$
\ln \gamma_{\mathrm{i}}=1-\ln \left(\sum_{\mathrm{j}} \mathrm{A}_{\mathrm{ij}} \mathrm{x}_{\mathrm{j}}\right)-\sum_{\mathrm{j}} \frac{\mathrm{A}_{\mathrm{ji}} \mathrm{x}_{\mathrm{j}}}{\sum_{\mathrm{k}} \mathrm{A}_{\mathrm{jk}} \mathrm{x}_{\mathrm{k}}}
$$

$$
\ln \mathrm{A}_{\mathrm{ij}}=\mathrm{a}_{\mathrm{ij}}+\frac{\mathrm{b}_{\mathrm{ij}}}{\mathrm{T}}
$$

Table 5. Herington test for thermodynamic consistency check.

\begin{tabular}{lccc}
\hline \multicolumn{1}{c}{ System } & $\boldsymbol{D}$ & $\boldsymbol{J}$ & $\mid \boldsymbol{D}-\boldsymbol{J}<\mathbf{1 0}$ \\
\hline Cyclohexane (1) + Isopropyl chloroacetate (2) & 37.73 & 29.26 & 8.47 \\
Isopropanol (1) + Isopropyl chloroacetate (2) & 37.68 & 28.61 & 9.08 \\
Benzene (1) + Isopropyl chloroacetate (2) & 37.89 & 29.19 & 8.69 \\
\hline
\end{tabular}


UNIQUAC:

$\ln \gamma_{i}=\ln \frac{\Phi_{i}}{x_{i}}+\frac{z}{2} q_{i} \ln \frac{\theta_{i}}{\Phi_{i}}-q_{i}^{t} \ln t_{i}^{t}-q_{i}^{t} \frac{\sum_{j}^{t} \tau_{j}^{t} \tau_{i j}}{t_{j}^{t}}+1_{i}+q_{i}^{t}-\frac{\Phi_{i}}{x_{i}} \sum_{j} x_{j} 1_{j}$

$\tau_{i j}=\exp \left(a_{i j}+\frac{b_{i j}}{T}\right)$

$\mathrm{l}_{\mathrm{i}}=\left(\frac{\mathrm{z}}{2}\right)\left(\mathrm{r}_{\mathrm{i}}-\mathrm{q}_{\mathrm{i}}\right)\left(\mathrm{r}_{\mathrm{i}}-1\right)$

$\Phi_{i}=\frac{r_{i} x_{i}}{\sum_{k} r_{k} x_{k}}$

$\theta_{i}=\frac{q_{i} x_{i}}{\sum_{k} q_{k} x_{k}}$

The interaction parameters of the above three models were obtained based on the maximum likelihood method by minimizing the following objective equation:

$Q=\sum_{i=1}^{N}\left[\left(\frac{T_{i}^{\text {exp }}-T_{i}^{\text {cal }}}{\sigma_{T}}\right)^{2}+\left(\frac{p_{i}^{\text {exp }}-p_{i}^{\text {cal }}}{\sigma_{p}}\right)^{2}+\left(\frac{x_{i}^{\text {exp }}-x_{i}^{\text {cal }}}{\sigma_{x}}\right)^{2}+\left(\frac{y_{i}^{\text {exp }}-y_{i}^{\text {cal }}}{\sigma_{y}}\right)^{2}\right]$

The obtained interaction parameters of the NRTL, Wilson and UNIQUAC models in Aspen plus simulator (2013) are listed in Table 8. The root-meansquare deviations $(R M S D)$ were employed to evaluate the difference between the experimental and the calculated results. The RMSD $\left(y_{\mathrm{i}}\right)$ and $R M S D(T)$ are as follows:

$\operatorname{RMSDy}_{\mathrm{i}}=\sqrt{\sum_{\mathrm{i}=1}^{\mathrm{N}} \frac{\left(\mathrm{y}_{\mathrm{i}}^{\text {exp }}-\mathrm{y}_{\mathrm{i}}^{\text {cal }}\right)^{2}}{\mathrm{~N}}}$
Table 7. Structural parameters for the UNIQUAC equation. ${ }^{\mathrm{a}}$

\begin{tabular}{lcc}
\hline \multicolumn{1}{c}{ Component } & $\boldsymbol{r}$ & $\boldsymbol{q}$ \\
\hline Isopropyl chloroacetate & 4.663 & 4.064 \\
Cyclohexane & 4.047 & 3.240 \\
Isopropanol & 2.914 & 2.528 \\
Benzene & 3.191 & 2.400 \\
\hline
\end{tabular}

a The structural parameters were taken from the Aspen plus physical properties databank.

$\operatorname{RMSDT}_{\mathrm{i}}=\sqrt{\sum_{\mathrm{i}=1}^{\mathrm{N}} \frac{\left(\mathrm{T}_{\mathrm{i}}^{\text {exp }}-\mathrm{T}_{\mathrm{i}}^{\text {cal }}\right)^{2}}{\mathrm{~N}}}$

The calculated $R M S D$ values with the correlated parameters are presented in Table 8 , which are less than $0.58 \mathrm{~K}$ and 0.006 respectively. As is shown in Table 8, the NRTL, Wilson and UNIQUAC models could correlate the VLE data for the three binary systems. Since the calculated results by the three model were graphically similar, the results correlated by the NRTL model were plotted in Figures 2-4.

According to the residuals of temperature and vapor mole fraction, the reliability of VLE data measured for each system has been checked (Orchillés et al., 2017; Mathias, 2017; Ma et al., 2018). Since the values of RMSD by the NRTL model were relatively larger than those of the Wilson and UNIQUAC models, the residuals of temperature and vapor mole fraction were calculated based on the difference between experimental values and the calculated values in the NRTL model. The residuals for the vapor mole fraction and temperature are less than 0.016 and 0.010 and are presented in Figures 7 and 8. As shown in Figures. 7 and 8, the distributions of the vapor phase mole fraction and temperature residuals are randomly distributed around zero. The fluctuations of the vapor phase mole fraction and temperature residual values are within the range between -0.016 and 0.012 , and -0.005 and 0.010 respectively.

Table 8. The interaction parameters and root-mean-square deviations (RMSD) for binary systems.

\begin{tabular}{|c|c|c|c|c|c|c|}
\hline Model & $a_{i j}$ & $a_{j i}$ & $\boldsymbol{b}_{i j} / \mathbf{K}$ & $\boldsymbol{b}_{j i} / \mathbf{K}$ & $R M S D\left(y_{I}\right)$ & $R M S D(T)$ \\
\hline \multicolumn{7}{|c|}{ Cyclohexane (1) + Isopropyl chloroacetate (2) } \\
\hline NRTL & -2.7539 & 0.4169 & 1533.43 & -395.50 & 0.0060 & 0.58 \\
\hline Wilson & 0.2585 & 1.7588 & 53.88 & -1074.49 & 0.0057 & 0.54 \\
\hline UNIQUAC & 0.3081 & 0.1710 & -348.10 & 84.15 & 0.0058 & 0.54 \\
\hline \multicolumn{7}{|c|}{ Isopropanol (1) + Isopropyl chloroacetate (2) } \\
\hline NRTL & -10.0839 & 20.3022 & 3438.09 & -6918.72 & 0.0038 & 0.26 \\
\hline Wilson & -12.0894 & 5.4616 & 3991.10 & -3936.35 & 0.0035 & 0.26 \\
\hline UNIQUAC & 4.6921 & -10.2046 & -1827.72 & 3360.08 & 0.0037 & 0.23 \\
\hline \multicolumn{7}{|c|}{ Benzene (1) + Isopropyl chloroacetate (2) } \\
\hline NRTL & -10.2641 & 24.2028 & 3497.51 & -8392.13 & 0.0064 & 0.23 \\
\hline Wilson & -16.4172 & 5.1950 & 5562.50 & -1693.54 & 0.0043 & 0.17 \\
\hline UNIQUAC & 4.8828 & -12.9678 & -1552.45 & 4364.27 & 0.0066 & 0.21 \\
\hline
\end{tabular}

${ }^{a}$ NRTL, $\tau_{i j}=\alpha_{i j}+b_{i j} / T$, the value of $\alpha_{i j}$ was set at 0.3 for binary systems.

${ }^{b}$ UNIQUAC, $\tau_{i j}=\exp \left(\alpha_{i j}+b_{i j} / T\right)$.

${ }^{c}$ Wilson, $\ln A_{i j}=\alpha_{i j}+b_{i j} / T$. 


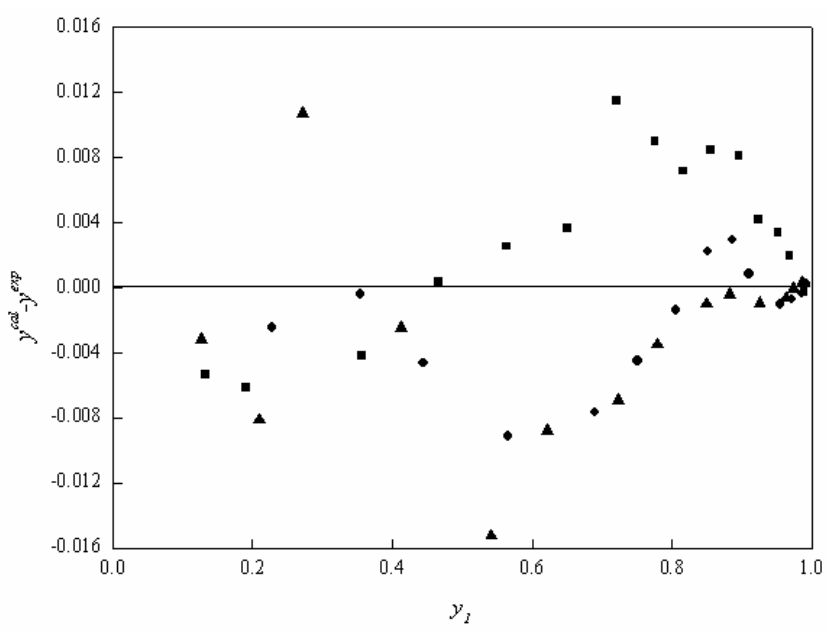

Figure 7. Residual plot of vapor mole fraction for the three systems: a, cyclohexane (1) + isopropyl chloroacetate (2); • , isopropanol (1) + isopropyl chloroacetate (2); $\boldsymbol{\Delta}$, benzene (1) + isopropyl chloroacetate (2).

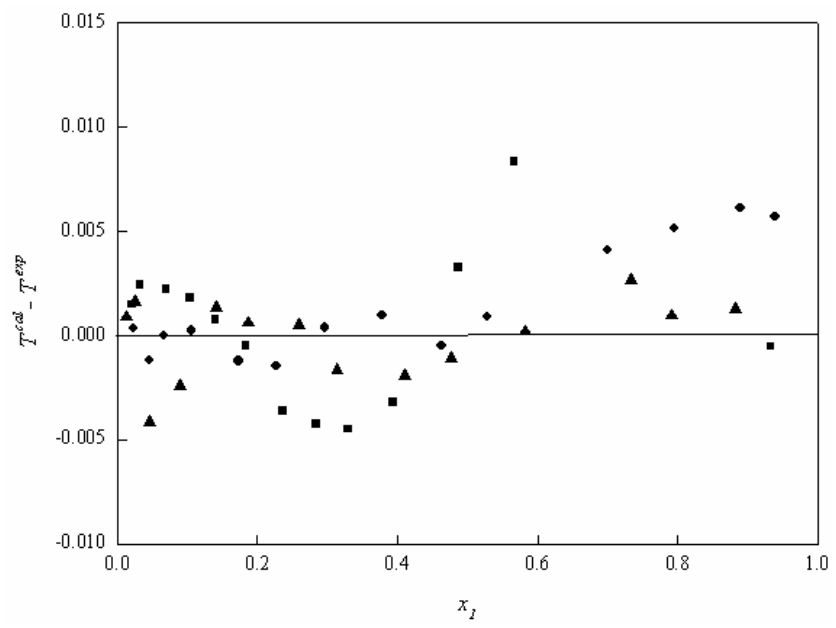

Figure 8. Residual plot of temperature for the three systems: $\mathbf{n}$, cyclohexane (1) + isopropyl chloroacetate (2); •, isopropanol (1) + isopropyl chloroacetate (2); $\boldsymbol{\Lambda}$, benzene (1) + isopropyl chloroacetate (2).

\section{CONCLUSIONS}

The VLE data for the binary solutions of isopropyl chloroacetate + cyclohexane, isopropyl chloroacetate + isopropanol and isopropyl chloroacetate + benzene were generated at $101.3 \mathrm{kPa}$. The calculated excess Gibbs energy results indicate that the three systems show positive deviations from Raoult's law. The thermodynamic consistency test for the experimental data was checked by the Herington and van Ness methods, and the measured VLE data passed the consistency tests. The thermodynamic models NRTL, Wilson, and UNIQUAC were adopted to fit the measured VLE data for the investigated systems and the binary interaction parameters of the models were regressed. The $R M S D$ values for the mole fraction of

vapor phase and the temperature were all less than $0.58 \mathrm{~K}$ and 0.0066 , respectively.

\section{ACKNOWLEDGEMENTS}

This work was supported by the Shandong Provincial Key Research \& Development Project (2018GGX107001), National Natural Science Foundation of China (21878178) and Project of Shandong Province Higher Educational Science and Technology Program (J18KA072).

\section{NOMENCLATURE}

$\mathrm{T}$

$\mathrm{p}$

$\mathrm{N}$

$\alpha$

r

q

Z

$\theta$

$\mathrm{u}$

$\mathrm{x}$

$\mathrm{y}$

$\phi_{\mathrm{i}}$

$\phi_{\mathrm{i}}{ }^{\mathrm{s}}$

$\gamma$

$\mathrm{V}_{\mathrm{i}}^{\mathrm{L}}$

$\mathrm{R}^{\mathrm{i}}$

$\mathrm{p}_{\mathrm{i}}^{\mathrm{s}}$

$\mathrm{p}_{\text {ci }}$

a, b

$\sigma$

i,j

cal

$\exp$
Equilibrium temperature (K)

Pressure $(\mathrm{kPa})$

The point of the experimental data

Non-randomness parameter in the

NRTL model

Area parameter of UNIQUAC

Volume parameter of UNIQUAC

Lattice coordination number in the UNIQUAC model

Area fraction in the UNIQUAC model

Uncertainty

Mole fraction in the liquid phase

Mole fraction in the vapor phase

Fugacity coefficient of the vapor phase

Fugacity coefficient at the saturated pressure

Activity coefficient

Liquid molar volume

Universal gas constant $\left(8.314 \mathrm{~J} . \mathrm{K}^{-1} \cdot \mathrm{mol}^{-1}\right)$

Saturation vapor pressure

Critical pressure of pure component

Binary interaction parameters

Standard deviation

Component i, j

Calculated property

Experimental property

\section{REFERENCES}

Aspen Plus Software, Aspen Technology, Inc., Burlington, MA, 2013, Version 8.4.

Abrams, D. S., Prausnitz, J. M. Statistical Thermodynamics of Liquid Mixtures: A New Expression for the Excess Gibbs Energy of Partly or Completely Miscible Systems. AIChE Journal, 21, 116-128 (1975). https://doi.org/10.1002/ aic.690210115

Acevedo, I. L., Posfigo, M. A., Katz, M. Excess Thermodynamic Properties and VaporLiquid Equilibrium Data for the n-Butylamine + p-Dioxane System at $25^{\circ} \mathrm{C}$. Journal of Solution Chemistry, 17, 977-986 (1988). https://doi.org/10.1007/ BF00649741 
Alinejhad, M., Shariati, A., Hekayati, J. Experimental Vapor-Liquid Equilibria and Thermodynamic Modeling of the Methanol + n-Heptane and 1-Butanol + Aniline Binary Systems. Journal of Chemical and Engineering Data, 63, 965-971 (2018). https://doi.org/10.1021/acs.jced.7b00766

Chen, R., Zhong, L., Xu, C. Isobaric Vapor-Liquid Equilibrium for Binary Systems of Toluene + Ethanol and Toluene + Isopropanol at (101.3, 121.3, 161.3, and 201.3) kPa. Journal of Chemical and Engineering Data, 57, 155-165 (2011). https:// doi.org/10.1021/je200921u

Dai, C., Lei, Z., Xi, X., Zhu, J., Chen, B. Extractive Distillation with a Mixture of Organic Solvent and Ionic Liquid as Entrainer. Industrial \& Engineering Chemistry Research, 53, 15786-15791 (2014). https://doi.org/10.1021/ie502487n

Dorris, T. B., Sowa, F. J., Nieuwland, J. A. Organic Reactions with Boron Fluoride. VIII. The Condensation of Propylene with Acids. Louis, F., Fieser, A. M. S., 56, 2689-2690 (1934). https://doi. org/10.1021/ja01327a048

Forero, G. L. A., Velásquez, J. J. A. Wagner LiquidVapour Pressure Equation Constants From a Simple Methodology. J. Chem. Thermodynamics, 43, 1235-1251 (2011). https://doi.org/10.1016/j. jet.2011.03.011

Gao, J., Li, H., Xu, D., Zhang, L., Zhao, L., Li, C. Isobaric Vapor-Liquid Equilibrium for Binary Systems of Thioglycolic Acid with Water, Butyl Acetate, Butyl Formate, and Isobutyl Acetate at $101.3 \mathrm{kPa}$. Journal of Chemical and Engineering Data, 62, 355-361 (2016a). https://doi.org/10.1021/ acs.jced.6b00686

Gao, J., Zhao, L., Zhang, L., Xu, D., Zhang, Z. Isobaric Vapor-Liquid Equilibrium for Binary Systems of 2,2,3,3-Tetrafluoro-1-propanol + 2,2,3,3,4,4,5,5-Octafluoro-1-pentanol at 53.3, 66.7, $80.0 \mathrm{kPa}$. Journal of Chemical and Engineering Data, 61, 3371-3376 (2016b). https://doi. org/10.1021/acs.jced.6b00429

Gupta, B. S., Lee, M.-J. Isobaric Vapor-Liquid Equilibrium for the Binary Mixtures of Nonane with Cyclohexane, Toluene, M-xylene, or P-xylene at $101.3 \mathrm{kPa}$. Fluid Phase Equilibria, 313, 190-195 (2012). https://doi.org/10.1016/j.fluid.2011.10.009

Herington, E. F. G., Inst, J. Tests for the Consistency of Experimental Isobaric Vapour-Liquid Equilibrium Data. Journal of the Institution of Petroleum, 37 , 457-470 (1951).

Li, J., Hua, C., Xiong, S., Bai, F., Lu, P., Ye, J. Vapor-Liquid Equilibrium for Binary Systems of Allyl Alcohol + Water and Allyl Alcohol + Benzene at $101.3 \mathrm{kPa}$. Journal of Chemical and Engineering Data, 62, 3004-3008 (2017). https:// doi.org/10.1021/acs.jced.6b00893
Li, Y. Measurement and correlation of isobaric vapor-liquid equilibrium for the binary system of cyclopentane and tetrahydrofuran. Brazilian Journal of Chemical Engineering, 31, 815$820 \quad$ (2014). https://doi.org/10.1590/01046632.20140313s00002623

Liu, D., Gui, J., Zhu, X., Song, L., Sun, Z. Synthesis and Characterization of Task-Specific Ionic Liquids Possessing Two Brönsted Acid Sites. Synthetic Communications, 37, 759-765 (2007).

Liu, S., You, H. An Overview on Synthetic Methods of Isopropyl Chloroacetate. European Chemical Bulletin, 1, 103-106 (2012).

Liu, S., You, H. Effect of the Different Reaction Conditions on Synthesizing of Isopropyl Chloroacetate. European Chemical Bulletin, 2, 9-10 (2013). https://doi.org/10.1016/j. molliq.2018.11.047

Liu, X., Xu, D., Diao, B., Zhang, L., Gao, J., Liu, D., Wang, Y. Choline chloride based deep eutectic solvents selection and liquid-liquid equilibrium for separation of dimethyl carbonate and ethanol. Journal of Molecular Liquids, 275, 347-353 (2019).

Ma, J., Jiang, H., Gong, H., Sun, Z. Esterification of Chloroacetic Acid with Alcohols Catalyzed by Zinc Methanesulfonate. Petroleum Science and Technology, 24, 431-440 (2006). https://doi. org/10.1081/LFT-200043689

Ma, Y., Gao, J., Li, M., Zhu, Z., Wang, Y. Isobaric Vapour-Liquid Equilibrium Measurements and Extractive Distillation Process for the Azeotrope of (N, N-dimethylisopropylamine + acetone). Journal of Chemical Thermodynamics, 122, 154-161 (2018). https://doi.org/10.1016/j.jct.2018.03.019

Mathias, P. M. Guidelines for the Analysis of VaporLiquid Equilibrium Data. J. Chem. Eng. Data, 62, 2231-2233 (2017). https://doi.org/10.1021/acs. jced.7b00582

Orchillés, A. V., Miguel, P. J., González-Alfaro, V., Llopis, F. J., Vercher, E., Martínez-Andreu, A. Isobaric Vapor-Liquid Equilibria for the Extractive Distillation of 2-Propanol + Water Mixtures Using 1-ethyl-3-methylimidazolium Dicyanamide Ionic Liquid. Journal of Chemical Thermodynamics, 110, 16-24 (2017). https://doi.org/10.1016/j. jet.2017.02.005

Patwardhan, A. A., Sharma, M. M. Esterification of Carboxylic Acids with Olefins Using Cation Exchange Resins as Catalysts. Reactive Polymers, 13, 161-176 (1990). https://doi.org/10.1016/09231137(90)90051-5

Renon, H., Prausnitz, J. M. Local Compositions in Thermodynamic Excess Functions for Liquid Mixtures. AlChE Journal, 14, 135-144 (1968). https://doi.org/10.1002/aic.690140124 
Shi, P., Gao, Y., Wu, J., Xu, D., Gao, J., Ma, X., Wang, Y. Separation of azeotrope (2,2,3,3-tetrafluoro1-propanol + water): Isobaric vapour-liquid phase equilibrium measurements and azeotropic distillation. Journal of Chemical Thermodynamics, 115, 19-26 (2017). https://doi.org/10.1016/j. jct.2017.07.019

Smith, J. M., Van, N. H. C., Abbott, M. M. Introduction to Chemical Engineering Thermodynamics. sixth (ed). McGraw-Hill, New York (2001).

Van Ness, H. C., Byer, S. M., Gibbs, R. E. VaporLiquid Equilibrium: part I. An appraisal of data reduction methods. AIChE Journal, 19, 238-244 (1973). https://doi.org/10.1002/aic.690190206

Wang, M., Tian, J., Liu, L., Jiang, H., Gong, H., Su, T. Synthesis and Characterization of MethaneSulfonates and Their Catalytic Activities for
Esterification. Chinese Journal of Inorganic Chemistry, 19, 731-734 (2003).

Wilson, G. M. A New Expression for The Excess Free Energy of Mixing. Journal of the American Chemical Society, 86, 127-130 (1964). https://doi. org/10.1021/ja01056a002

Wu, J., Xu, D., Shi, P., Gao, J., Zhang, L., Ma, Y., Wang, Y. Separation of azeotrope (allyl alcohol + water): Isobaric vapour-liquid phase equilibrium measurements and extractive distillation. Journal of Chemical Thermodynamics, 118, 139-146 (2018). https://doi.org/10.1016/j.jct.2017.11.009

$\mathrm{Xu}$, J., Zhang, J., Yin, X. Esterification Process to Synthesize Isopropyl Chloroacetate Catalyzed by Lanthanum Dodecyl Sulfate. Brazilian Journal of Chemical Engineering, 28, 259-264 (2011). https:// doi.org/10.1590/S0104-66322011000200010 
